\title{
Multi-Objective Design of Profit Volumes and Closeness Ratings Using MBHS Optimizing Based on the PrefixSpan Mining Approach (PSMA) for Product Layout in Supermarkets
}

\author{
Jakkrit Kaewyotha $(\mathbb{B}$ and Wararat Songpan *
}

Department of Computer Science, Khon Kaen University, Khon Kaen 40002, Thailand; jakkrit_kaewyotha@kkumail.com

* Correspondence: wararat@kku.ac.th

Citation: Kaewyotha, J.; Songpan, W. Multi-Objective Design of Profit Volumes and Closeness Ratings Using MBHS Optimizing Based on the PrefixSpan Mining Approach (PSMA) for Product Layout in Supermarkets. Appl. Sci. 2021, 11, 10683. https:// doi.org/10.3390/app112210683

Academic Editor: Byung-Gyu Kim

Received: 24 September 2021

Accepted: 8 November 2021

Published: 12 November 2021

Publisher's Note: MDPI stays neutral with regard to jurisdictional claims in published maps and institutional affiliations.

Copyright: () 2021 by the authors. Licensee MDPI, Basel, Switzerland. This article is an open access article distributed under the terms and conditions of the Creative Commons Attribution (CC BY) license (https:// creativecommons.org/licenses/by/ $4.0 /)$.

\begin{abstract}
Product layout significantly impacts consumer demand for purchases in supermarkets. Product shelf renovation is a crucial process that can increase supermarket efficiency. The development of a sequential pattern mining algorithm for investigating the correlation patterns of product layouts, solving the numerous problems of shelf design, and the development of an algorithm that considers in-store purchase and shelf profit data with the goal of improving supermarket efficiency, and consequently profitability, were the goals of this research. The authors of this research developed two types of algorithms to enhance efficiency and reach the goals. The first was a PrefixSpan algorithm, which was used to optimize sequential pattern mining, known as the PrefixSpan mining approach. The second was a new multi-objective design that considered the objective functions of profit volumes and closeness rating using the mutation-based harmony search (MBHS) optimization algorithm, which was used to evaluate the performance of the first algorithm based on the PrefixSpan algorithm. The experimental results demonstrated that the PrefixSpan algorithm can determine correlation rules more efficiently and accurately ascertain correlation rules better than any other algorithms used in the study. Additionally, the authors found that MBHS with a new multi-objective design can effectively find the product layout in supermarket solutions. Finally, the proposed product layout algorithm was found to lead to higher profit volumes and closeness ratings than traditional shelf layouts, as well as to be more efficient than other algorithms.
\end{abstract}

Keywords: data mining; product layout; sequential pattern mining; supermarket; harmony search algorithm

\section{Introduction}

Sequential pattern mining (SPM) is a sequential pattern query technique used to find data correlations during transactions; it was first presented by Agrawal and Srikant [1-3]. Currently, due to competition in the retail industry, supermarkets are trying to improve their revenue by becoming more efficient and, therefore, profitable. Usually, supermarkets keep records of their customers' purchases. This shopping information can be used to find the most common purchasing patterns. Therefore, sequential pattern mining has been applied to determine purchasing patterns with common purchasing frequencies. Previous studies [4-9] have presented models for determining the groupings of product series on shelves in order to maximize profits. Product layout can not only catch the eyes and draw the attention of consumers but also increase customer purchases and satisfaction. Previous studies [10-13] have also implemented sequential pattern mining to explore frequent sequential patterns, which are considered necessary for determining the frequency of product purchases [14].

There are two key issues that must be considered in shelf management: shelf management strategies and purchases frequencies. Product shelf management strategies, which are under the umbrella of shelf layout, directly influence customers' purchasing decisions and 
affect store profits. It is also challenging to manage shelf displays to increase sales without first considering the product layout. The challenges of shelf layouts and patterns have caught the attention of market researchers. The authors of [15-18] found that factors that may significantly influence customers' purchasing decisions include shelf space allocation and layout display. Personal or social factors may also influence the urge to purchase another product, a phenomenon that has been studied via Market Basket Analysis [19-25], which analyzes the correlation of products that customers are most likely to buy at the same time [26-28]. The management of shelf space was found to be a problem affecting consumers' purchasing behaviors; the effectiveness of shelf layouts between nearby supermarkets was compared to investigate how to increase profits and improve customer satisfaction [29-31]. To deal with this critical problem, a PrefixSpan algorithm [32-34] has been implemented. Prior to this algorithm, authors [35-38] paid attention to the management of the location of each specific shelf in a supermarket. Although this method is able to increase sales, it does not consider possible correlations between products on different shelves by analyzing customers' shopping lists, a gap that could lead to crucial sales losses.

Sequential patterns can be determined with various algorithms, such as the Apriori, GSP, Freespan [32-34], and projection-based PrefixSpan algorithms. The PrefixSpan algorithms can be used to mine sequence patterns and count the frequency of item sets in search spaces without the need for candidate generation. It can also be used for small-scaled problem solving to better increase consumer efficiency compared to other algorithms. In contrast to the GSP algorithm, the PrefixSpan algorithm can even be used to search for local minima and scan sequences patterns. To summarize, the PrefixSpan algorithm can effectively improve consumer time efficiency and filter redundant patterns, and the metaheuristic method can be used to aid the algorithm's pattern optimization.

Aspects of the metaheuristic method have been employed to optimize answer or fitness values when solving complex problems. Well-known metaheuristic algorithms include the genetic algorithm (GA) [39], genetic programming (GP), evolutionary programming (EP), particle swarm optimization (PSO) [40,41], simulated annealing (SA) [42], artificial bee colony $(\mathrm{ABC})[43,44]$, and harmony search (HS) [45-48]. The HS algorithm is an evolutionary algorithm used to find fitness values based on the problem-solving principles of musicians. It is a method that mimics the way a musician improvises, improves, and finds the perfect state of harmony, also known as the objective function. In [49-52], the harmony search algorithm showed an extremely high performance for solving the problems of the search space compared to other evolutionary algorithms.

The contributions of this study are three main points as follows: first, we propose the sequential pattern mining algorithm, the PrefixSpan algorithm, to analyze customers' purchasing behaviors and find shelf and product correlations to filter the pattern of product. Firstly, we compared the performance of the PrefixSpan algorithm and other methods, thus revealing the advantages of the former. Second, a combination of the metaheuristic algorithm with PrefixSpans, the MBHS, is designed with the multi-objective function including the pattern of PrefixSpans, which is given a suitable pattern length. This study solved the problem of the sequence mining pattern and design in the population as a set of optimal answers in MBHS. Additionally, we proposed the multi-objective as two issues: profit and closeness rating to enhance the product layout in a supermarket. This aspect of performance was better than others in improving shelf layouts compared to traditional methods. These purposed algorithms with the multi-objective design focus on a profits-derived closeness rating between shelves to redesign store layouts. Finally, this study was proposed to investigate sequential pattern mining and shelf layouts to improve not only individual shelf layouts, in contrast to previous research, but also the overall products on shelves in supermarket layouts and performance. Thus, the authors of this study propose a novel metaheuristic sequential pattern mining technique using MBHS based on the PrefixSpan Mining approach for an analysis of the behavior of customer purchase data to improve the entire product in supermarkets and shelf layouts to increase profitability and enhance the closeness rating. 


\section{Related Work}

A wide variety of studies have proposed the use of sequential pattern mining to solve the problems of shelf management and layout. The authors of [53] proposed a timeliness variable threshold for sequential patterns, with a focus on finding pyramid scheme patterns in both individual and different sequences. The authors of this study employed the abovementioned method with real financial data to analyze sequential time intervals. The authors of [54] proposed the use of the PrefixSpan algorithm to generate sequential patterns to create a personalized product recommendation system. Its aim was for users to be able to buy the best products in the shortest possible time, and the research presented a cross-domain recommendation by employing ontology while solving the problem. The experimental results showed that it could help alleviate the problems of new users to some extent. The authors of [55] studied a cloud service-customized product information system. They collected three types of data: e-commerce services, promotiontype modules, and cloud service-customized promotional products. The purposes of the study were to generate and propose a system for detecting customers' behaviors. Marketing data were analyzed by employing an association rule mining algorithm and sequential pattern mining. The experimental results of this research revealed that the SPM method could effectively analyze customer behavior data and search for information regarding product promotion with the goal of evaluating sales and increasing production. The authors of [56] proposed the use of commonsense knowledge (CSK) in a machine-learning application, which was compared with human behavior, and the application was found to improve common-sense decision-making and enhance data mining.

The authors of [57] suggested that the backroom was the most important part of retail, so they focused on optimizing the distribution center and sales spaces of a store. They proposed a solution for the problem of grocery backroom sizing to reduce floor space, which may result in higher revenues and/or lower backroom-associated costs. The authors of [58] proposed a framework for sequential pattern mining to find a pattern that was more complex and more difficult than what was currently available. Such a pattern was found in the data regarding individual self-management. The findings of this study were also applied to the American Time Use Survey (ATUS) dataset to explore individual timeallocation behaviors and identify sequences of activities, e.g., which patterns of activities need to be performed first and later, a sequence known as the frequency. The authors of [59] proposed an analysis method based on the Poisson model that considers impactable parameters, such as the time of the day, day of the week, and week of the month, to investigate a source of variation in a case study from Chile. The authors of [37] proposed the use of the Map-Reduce algorithm in conjunction with sequential pattern mining to find correlations between groups of products. The data were randomized for sequential pattern mining with the aim of finding the most profitable products in order to improve the overall profitability of a supermarket. The authors of [60] found problems in analyses of travelling data and ineffective tourism management because the existing techniques were unable to capture the sequential patterns of hidden tourist data. After researching a case study of Australian outbound tourism, the authors suggested a solution that comprised an analysis of travelers' behaviors through location-tagging photos and the use of sequential pattern mining. The efficacy of the proposed method demonstrated the benefits of promoting tourism and presenting suitable destinations for tourists. The authors of [61] applied itembased collaborative filtering with an Apriori-based model to find patterns in an e-commerce service. The disadvantages of this filtering system included redundant rules and sequential patterns, so further improvements are required.

The PrefixSpan algorithm was compared with sequential patterns, such as the Apriori algorithm, GSP algorithm, and Freespan algorithm. The performance of the PrefixSpan algorithm is significantly higher than the others $[62,63]$. Moreover, the PrefixSpan had a consuming time that was faster than the others because the proposed algorithm was not generated from the frequency of items within the search space in the projected databases. However, the PrefixSpan's long pattern length is a limitation. Researchers have expressed 
interest in prefix algorithms and their improvements [46,56-59]. The study of [59] is relevant to this paper from an application standpoint, as it revealed that shelf layout affects the display of available food items, information that could be useful in mobile applications. The authors of [64] proposed a sequential pattern mining method for supermarkets that is similar to our method, but our proposed method is different because it orders products in regard to both their shelves and individual profit. A common problem in sequential pattern mining methods is still the criteria design, which should be solved by focusing on individual shelves and using the MBHS algorithm for multi-objective optimization. The MBHS algorithm is a population-based meta-heuristic optimization algorithm and can solve the complex problem to reach the optimal solution. In [65-68], the MBHS algorithm was developed to reduce the cost by objective function design, where the MBHS in many studies has different objective functions, and developed the combination of the search method with harmony search. The MBHS in our purposed methods is applied to the design as a multi-objective function combined with the identified sequential pattern in shelf layouts to enhance pattern generations with the aid of heuristic algorithms that have defined multi-object functions. These multi-objective functions were designed to filter and solve product layout problems. A list of related works, along with their methods and domains, is shown in Table 1.

Table 1. Related works, along with their methods and domains.

\begin{tabular}{|c|c|c|c|}
\hline Year & Related Works & Methods & Domains \\
\hline 2004 & J. Pei et al. [69] & PrefixSpan & Sequential pattern mining \\
\hline 2013 & G. Aloysius and D. Binu [64] & PrefixSpan & $\begin{array}{l}\text { Sequential pattern mining } \\
\text { for supermarkets }\end{array}$ \\
\hline 2016 & M. Chaudhari et al. [70] & $\begin{array}{l}\text { PrefixSpan with } \\
\text { GRC constraints }\end{array}$ & $\begin{array}{c}\text { Constraints in pattern } \\
\text { mining }\end{array}$ \\
\hline 2016 & L. Epstein et al. [59] & $\begin{array}{l}\text { Auto regressive } \\
\text { Poisson regression }\end{array}$ & Recommender system \\
\hline 2017 & N. Tandon et al. [56] & 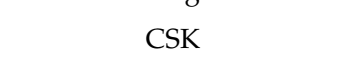 & $\begin{array}{c}\text { Machine-learning and smart } \\
\text { cities }\end{array}$ \\
\hline 2018 & X. Wang et al. [37] & SPM Map-Reduce & $\begin{array}{l}\text { Sequential pattern mining } \\
\text { for commodity management }\end{array}$ \\
\hline 2018 & H. Vu et al. [60] & Top-K SRM & Sequential pattern mining \\
\hline 2019 & T. Anwar and V. Uma [54] & CD-SPM & Recommender system \\
\hline 2019 & C. Hung [55] & CSIS & E-commerce services \\
\hline 2020 & M. Pires et al. [57] & $\begin{array}{c}\text { DEA } \\
\text { Item-based }\end{array}$ & Optimum retail space \\
\hline 2020 & J. Lourenco et al. [61] & $\begin{array}{c}\text { collaborative filtering with } \\
\text { Apriori }\end{array}$ & E-commerce services \\
\hline 2021 & Varghese et al. [71] & $\begin{array}{l}\text { Mobile app } \\
\text { development }\end{array}$ & Smart cities \\
\hline 2021 & W. Wang et al. [53] & TVI-PrefixSpan & $\begin{array}{l}\text { Sequential pattern mining } \\
\text { for pyramid scheme patterns }\end{array}$ \\
\hline
\end{tabular}

\section{Proposed Model}

The first part of this section discusses the implementation, procedures, and application of sequential pattern mining using the PrefixSpan algorithm to find all shelf correlations. The second part of this section discusses the development and procedures of the multi-objective mutation-based harmony search algorithm to solve the shelf management problem using the case study of a supermarket in Thailand.

\subsection{Sequential Pattern Mining}

Sequential patterns are like the concept of association rules, i.e., a sequence of transactions or lists of datasets are used to identify the frequency order of the data correlations. Each customer's list of purchases is different. However, every purchase appears in many transaction records. Sequential patterns are shown in the form $X \rightarrow Y$, where $X$ and $Y$ represent data obtained by surveying customers' purchase lists. The formulation of the sequential pattern mining method is completed only when the sequential rule is determined by two values. The first is support, which is the probability of the $\mathrm{X}$-value occurring 
in conjunction with the Y-value. Its value is between 0 and 1; if it approaches 1, a large number of this pattern occurs. This value can be obtained from Equation (1). The second is confidence, which is the probability of the $X$-value occurring in conjunction with the Y-value related to the sequence of events. This value can be obtained from Equation (2):

$$
\begin{gathered}
\operatorname{Support}(X \rightarrow Y)=P(X \cup Y) \\
\text { Confidence }(X \rightarrow Y)=\frac{P(X \cup Y)}{P(X)}
\end{gathered}
$$

\subsection{PrefixSpan Algorithm}

The PrefixSpan algorithm (prefix-projected sequential pattern mining), introduced by Jian Pei et al., was developed to optimize the processing of datasets. This algorithm (Algorithm 1) can help reduce the sizes of projected databases to process them more efficiently. Previous studies [72-74] have shown that the PrefixSpan algorithm outperforms other algorithms, such as the Apriori and Freespan algorithms, in finding the sequence patterns of big data. The basic definitions and steps of the PrefixSpan algorithm are defined as follows.

Definition 1 (Prefix). Let all items in an element be listed alphabetically or numerically. Given a sequence $\alpha=\left\langle e_{1} e_{2} \ldots e_{n}\right\rangle$, a sequence $\beta=\left\langle e_{1}^{\prime} e_{2}^{\prime} \ldots e_{m}^{\prime}\right\rangle(m \leq n)$ is called a prefix of $\alpha$.

Definition 2 (Projection). Let sequences $\alpha$ and $\beta$ be such that $\beta$ is a subsequence of $\alpha(\beta \sqsubseteq \alpha)$. A subsequence $\alpha$ of sequence $\alpha\left(\alpha^{\prime} \sqsubseteq \alpha\right)$ is called a projection of $\alpha$.

Definition 3 (Postfix). Let $\alpha^{\prime}=\left\langle e_{1} e_{2} \ldots e_{n}\right\rangle$ be the projection of $\alpha$, the prefix $\beta=\left\langle e_{1} e_{2} \ldots e_{m-1} e_{m}^{\prime}\right\rangle$ $(m \leq n)$. Sequence $\gamma=e_{m}^{\prime \prime} e_{m+1} \ldots e_{n}$ is called the postfix of $\alpha$, denoted as $\gamma=\alpha / \beta$, where $e_{m}^{\prime \prime}=\left(e_{m}-e_{m}^{\prime}\right)$.

Definition 4 (Projected database). Let $\alpha$ be a sequential pattern in the department transaction database DT, the $\alpha$-projected database be mean DT $\left.\right|_{\alpha}$, and the collection of postfixes of sequences in DT be prefix $\alpha$.

Definition 5 (Support count-projected database). Let $\alpha$ be a sequential pattern in the department transaction database DT and $\beta$ be a sequence with prefix $\alpha$. The support count of $\beta$ in the $\alpha$-projected database DT $\left.\right|_{\alpha}$ is the number of sequences $\gamma$ in DT $\left.\right|_{\alpha}$ such that $(\beta \sqsubseteq \alpha \cdot \gamma)$.

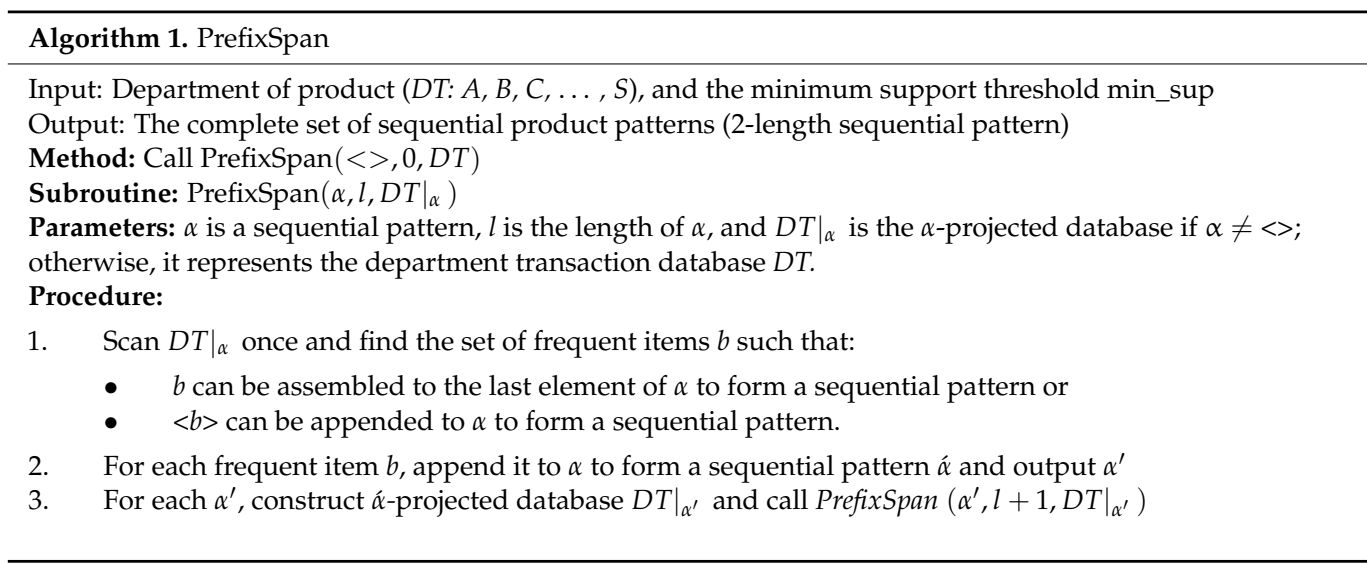

PrefixSpan for Finding Sequence Patterns

Before processing the purchase data for the PrefixSpan algorithm in the initial step, the preparation dataset or transaction database must be prepared. The data used for this experiment comprised customers' shopping lists from a case study of a supermarket in 
Thailand. The hierarchical structure of the supermarket's products is shown in Figure 1. In Figure 1, the hierarchical structure is divided into three levels: Level 0, Level 1, and Level 2. Level 1 contains a total of 49,688 items. This is linked to Level 2, which consists of different products. In Level 1, there are 19 departments. The purchase data are stored in the database shown in Table 2. An example database of customer purchase lists is shown in Table 2, which shows the order and product IDs representing customers' lists and purchased products, respectively. Table 3 shows information about product shelves sorted by department. Table 4 shows the profit of each shelf, as calculated from the total transactions. Table 5 was created to manage data from Tables 2 and 3 because this study focused on solving product shelf management problems by managing product information. In Table 5, the details of the correlation between departments and products are replaced by lists of items purchased (originally shown in Table 2) sorted by department (originally shown in Table 3), represented by Di. The data from Table 5 could then be further processed while identifying sequence patterns using the PrefixSpan algorithm.

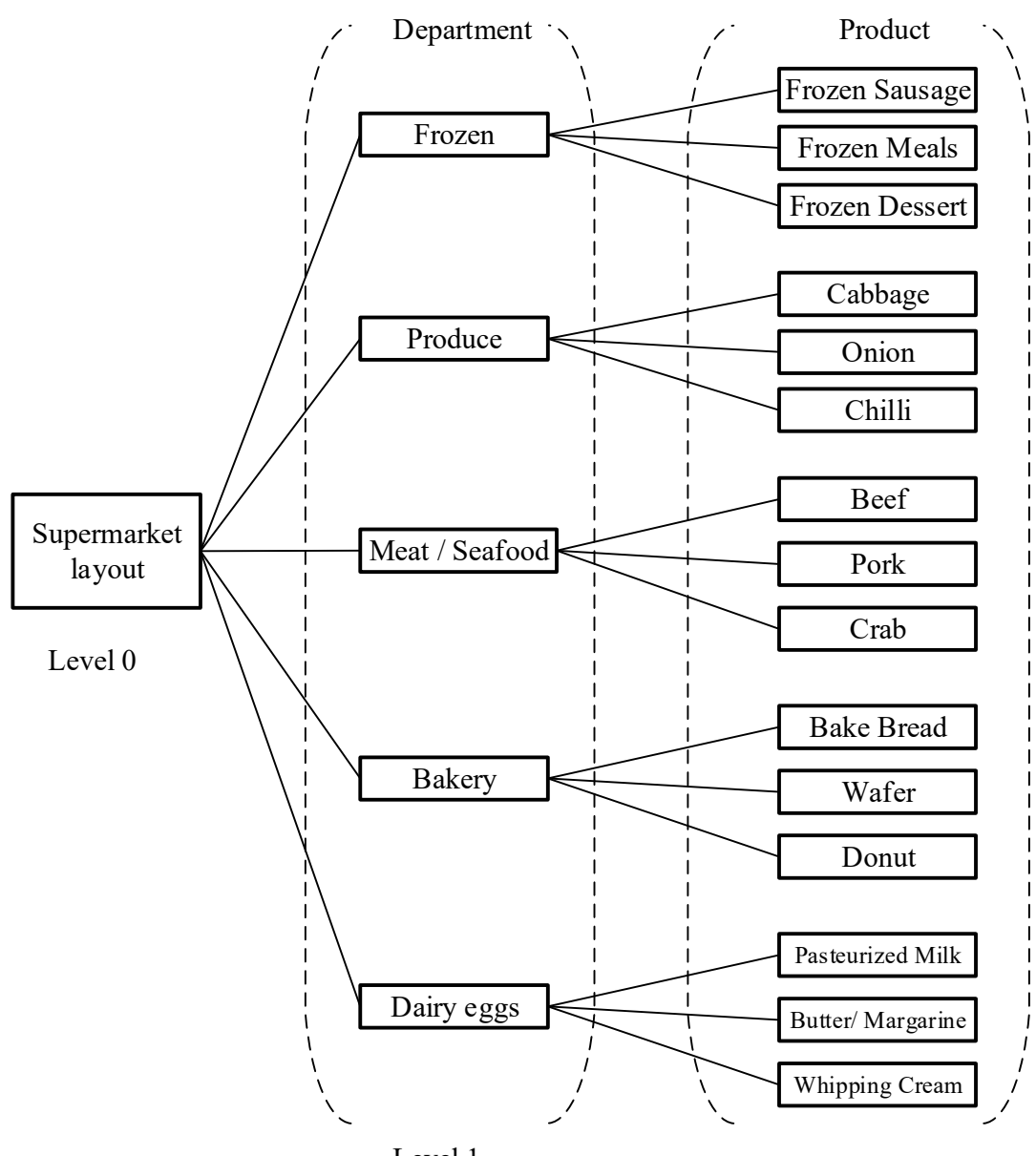

Level 1

Level 2

Figure 1. Hierarchical structure of supermarket products.

Table 2. A supermarket's order transaction database.

\begin{tabular}{cc}
\hline Order ID & Product ID \\
\hline 1 & $8,317,4264,3008,289$ \\
2 & $12,150,11432,4055$ \\
\hline
\end{tabular}


Table 3. Examples of departments.

\begin{tabular}{ccc}
\hline Department & Department Name & Product ID \\
\hline A & Frozen & $4,8,12,18,46,1176,1268,49636$ \\
B & Bakery & $58,245,317,346,15369,28129,46065$ \\
C & Produce & $89,380,4264,7805,11432,23429,48825$ \\
D & Alcohol & $150,3008,5810,10532,32445$ \\
E & International & $425,1414,4055,6372,9942,42023$ \\
F & Beverages & $197,289,16514,25743,35027$ \\
G & Pets & $8445,11558,23337,32748,44480$ \\
H & Dry Goods and Pasta & $173,27675,28301,37469,41224$ \\
I & Bulk Food & $1000,12699,19628,22827,32232,42091$ \\
J & Personal Care & $113,280,11929,12172,30689,36905$ \\
K & Meat Seafood & $5770,7519,18975,20518$ \\
L & Pantry & $4401,4682,11503,26163,34720,41660$ \\
M & Breakfast & $510,1087,15477,23456$ \\
N & Canned goods & $626,1251,10173$ \\
O & Dairy Eggs & $432,505,894,953,1006$ \\
P & Household & $14,105,328,415,500$ \\
Q & Babies & $219,309,426,873,1202$ \\
R & Snacks & $1,16,145,164,212,213$ \\
S & Deli & $49,109,138,403,886$ \\
\hline
\end{tabular}

Table 4. Profits of departments.

\begin{tabular}{ccc}
\hline Department & Department Name & Profit \\
\hline A & Frozen & 500,111 \\
B & Bakery & 165,168 \\
C & Produce & 87,917 \\
D & Alcohol & 213,612 \\
E & International & 339,047 \\
F & Beverages & 240,790 \\
G & Pets & 58,603 \\
H & Dry Goods and Pasta & 32,417 \\
I & Bulk Food & 5669 \\
J & Personal Care & 396,602 \\
K & Meat Seafood & 181,856 \\
L & Pantry & 161,281 \\
M & Breakfast & 16,846 \\
N & Canned Goods & 73,052 \\
O & Dairy Eggs & 51,724 \\
P & Household & 462,062 \\
Q & Babies & 110,228 \\
S & Snacks & 188,293 \\
\hline
\end{tabular}

Table 5. Department transaction database.

\begin{tabular}{cc}
\hline Order ID & Department \\
\hline 1 & A, B, C, D, F \\
2 & A, D, C, E \\
3 & E, F, A, B, D, C \\
4 & E, A, F, C, B \\
\hline
\end{tabular}

Our steps before applying the PrefixSpan algorithm are as follows: first, we found the prefix (length-1) of sequential patterns. To find sequential patterns in the DT database, purchase data from the database were used for processing A, B, C, D, F, Order 2: A, D, C, E, Order 3: E, F, A, B, D, C, and Order 4: E, A, F, C, B. Here, <n > represents each product 
shelf. This step began with the scanning of the DT data from Table 5 to find all frequent items in the DT. Each entry in the DT was taken in length -1 to be a prefix defined by Definition 1. The example data in Table 5 show a total of 6 prefixes, where $<\mathrm{m}>$ : count is a pattern followed by a support count: $\langle\mathrm{A}\rangle: 1,\langle\mathrm{~B}\rangle: 3,\langle\mathrm{C}\rangle: 4,\langle\mathrm{D}\rangle: 3,\langle\mathrm{E}\rangle: 3$, and $\langle\mathrm{F}\rangle: 3$. Then, we divided the search space. A set of six prefixes of sequential patterns $\langle A\rangle$, $\langle\mathrm{B}\rangle,\langle\mathrm{C}\rangle,\langle\mathrm{D}\rangle,\langle\mathrm{E}\rangle$, and $\langle\mathrm{F}\rangle$-were obtained from Step 1 . The number of the projection database depended on $\langle n\rangle$, where $\langle n\rangle$ is the subsets of the projection database. The data in Table 5 were used to find the projection comprising $\{A, B, C, D, E, F\}$. An example of the projection database format $\angle A>$ from the first row of data in the DT database is $\angle A, B, C, D$, $\mathrm{F}\rangle$, since the pattern $\langle\mathrm{A}\rangle$ is a projection defined by Definition 2 . The patterns $\langle\mathrm{B}, \mathrm{C}, \mathrm{D}, \mathrm{F}\rangle$ were found to be postfixes of the pattern $\angle A>$ by Definition 3 . The projected database of the pattern $\langle\mathrm{A}\rangle$ was found to contain $\langle\mathrm{B}, \mathrm{C}, \mathrm{D}, \mathrm{F}\rangle,\langle\mathrm{D}, \mathrm{C}, \mathrm{E}\rangle,\langle\mathrm{B}, \mathrm{D}, \mathrm{C}\rangle$, and $\langle\mathrm{F}, \mathrm{C}, \mathrm{B}\rangle$. Other forms of postfix from $<\mathrm{B}>$ to $<\mathrm{n}>$ were the same. The projected data are displayed in Table 6.

Table 6. Projected database.

\begin{tabular}{|c|c|}
\hline Prefix & Projected Postfix Database \\
\hline A & $\left.<_{-}, \mathrm{B}, \mathrm{C}, \mathrm{D}, \mathrm{F}\right\rangle_{,}<_{-}, \mathrm{D}, \mathrm{C}, \mathrm{E}>,<_{-}, \mathrm{B}, \mathrm{D}, \mathrm{C}>_{,}<_{-} \mathrm{F}, \mathrm{C}, \mathrm{B}>$ \\
\hline $\mathrm{B}$ & $<\mathrm{A}, \mathrm{C}, \mathrm{D}, \mathrm{F}>,<\ldots, \mathrm{D}, \mathrm{C}>$ \\
\hline $\mathrm{C}$ & $<\_, \mathrm{D}, \mathrm{F}>,<_{-}, \mathrm{E}>,<_{-}, \mathrm{B}>$ \\
\hline $\mathrm{D}$ & $<\_\mathrm{F}>,<_{-}, \mathrm{C}, \mathrm{E}>,<_{-}, \mathrm{C}>$ \\
\hline $\mathrm{E}$ & $<{ }_{-}, \mathrm{F}, \mathrm{A}, \mathrm{B}, \overline{\mathrm{D}}, \mathrm{C}>,<_{-}, \overline{\mathrm{A}}, \mathrm{F}, \mathrm{C}, \mathrm{B}>$ \\
\hline
\end{tabular}

Then, we found subsets of sequential patterns. In this step, subsets of sequential patterns were used to find a set of 2-length patterns from projected databases, and the process of finding sequential patterns was repeated until every transaction was completed. Following Definition 5, a sequential pattern and support count were used to find the support and confidence values with Equations (1) and (2).

The procedure found the prefix (length-1) of the sequential patterns for $\langle A>$, specifically transactions that consisted of $<\mathrm{A}>$ by only considering postfixes that occurred after the prefixed $\langle\mathrm{A}\rangle$. For example, Order 3 was found to contain $\langle\mathrm{E}, \mathrm{F}, \mathrm{A}, \mathrm{B}, \mathrm{D}, \mathrm{C}\rangle$, which has $<$ A $>$ as a prefix.

From the prefix $\left\langle\mathrm{A}>\right.$, only the subsequence $<_{-}, \mathrm{B}, \mathrm{D}, \mathrm{C}>$ was considered for sequential patterns of $\left\langle\mathrm{A}>\right.$. Note that $<_{-}>$represents the location of the prefix. $<\mathrm{A}>$ was found first in 2-length sequential patterns. From the DT database with $<\mathrm{A}>$ as the projected database, we found postfix sequences consisting of $\left.\left.\left.<_{-}, \mathrm{B}, \mathrm{C}, \mathrm{D}, \mathrm{F}\right\rangle_{,}<_{-}, \mathrm{D}, \mathrm{C}, \mathrm{E}\right\rangle_{,}<_{-}, \mathrm{B}, \mathrm{D}, \mathrm{C}\right\rangle_{,}<_{-} \mathrm{F}, \mathrm{C}, \mathrm{B}>$. We found the following 2-length sequential patterns with $<$ A $>$ as the prefix: $<A, B>: 3,<A$, $\mathrm{C}>: 4,<\mathrm{A}, \mathrm{D}>: 3,<. \mathrm{A}, \mathrm{F}>: 2$, and $<\mathrm{A}, \mathrm{E}>: 1$, where $<$ pattern $>$ : count represents the pattern followed by the frequency. The process of finding the 2-length sequential patterns of the $<\mathrm{B}>$-projected database and $<n>$-projected database could be repeatedly recreated and searched, just like the $<A>$-projected database shown in Table 7 . Then, sequential patterns from Table 7 were calculated to find support and confidence values. An example of the obtained results is shown in Table 8.

Table 7. Projected database and sequential patterns.

\begin{tabular}{|c|c|c|}
\hline Prefix & Projected Postfix Database & Sequential Patterns \\
\hline A & $\begin{aligned}<{ }_{-} \mathrm{B}, \mathrm{C}, \mathrm{D}, \mathrm{F}> & ,<_{-}, \mathrm{D}, \mathrm{C}, \mathrm{E}>,<_{{ }^{\prime}} \mathrm{B}, \mathrm{D}, \mathrm{C}> \\
& <\mathrm{F}, \mathrm{C}, \mathrm{B}>\end{aligned}$ & $<\mathrm{A}, \mathrm{B}\rangle,<\mathrm{A}, \mathrm{C}>,<\mathrm{A}, \mathrm{D}\rangle,<\mathrm{A}, \mathrm{F}\rangle,<\mathrm{A}, \mathrm{E}>$ \\
\hline $\mathrm{B}$ & $<{ }_{-} \mathrm{C}, \mathrm{D}, \mathrm{F}>,<_{-}, \mathrm{D}, \mathrm{C}>$ & $<\mathrm{B}, \mathrm{C}>,<\mathrm{B}, \mathrm{D}>,<\mathrm{B}, \mathrm{F}>$ \\
\hline C & $<\ldots, \mathrm{D}, \mathrm{F}>,<_{-}, \mathrm{E}>,<_{-}, \mathrm{B}>$ & $<\mathrm{C}, \mathrm{D}\rangle,\langle\mathrm{C}, \mathrm{F}\rangle,\langle\mathrm{C}, \mathrm{E}\rangle,<\mathrm{C}, \mathrm{B}\rangle$ \\
\hline $\mathrm{D}$ & $<\_\mathrm{F}>,<\ldots, \mathrm{C}, \mathrm{E}>,<{ }_{-} \mathrm{C}>$ & $<\mathrm{D}, \mathrm{F}>,<\mathrm{D}, \mathrm{C}>,<\mathrm{D}, \mathrm{E}>$ \\
\hline $\mathrm{E}$ & $<, \mathrm{F}, \overline{\mathrm{A}}, \mathrm{B}, \overline{\mathrm{D}}, \mathrm{C}>,<_{-}, \overrightarrow{\mathrm{A}}, \mathrm{F}, \mathrm{C}, \mathrm{B}>$ & $<\mathrm{E}, \mathrm{F}>,<\mathrm{E}, \mathrm{A}>,<\mathrm{E}, \mathrm{B}>,<\mathrm{E}, \mathrm{D}>,<\mathrm{E}, \mathrm{C}>$ \\
\hline
\end{tabular}


Table 8. Example sequence pattern result.

\begin{tabular}{cccc}
\hline No. & Department Pair & Support & Confidence \\
\hline 1 & Meat Seafood-Produce & $16.19 \%$ & $87 \%$ \\
2 & International-Produce & $6.46 \%$ & $87 \%$ \\
3 & Dry goods and Pasta-Dairy eggs & $16.38 \%$ & $83 \%$ \\
4 & Breakfast-Dairy eggs & $13.87 \%$ & $82 \%$ \\
5 & Frozen-Produce & $31.49 \%$ & $80 \%$ \\
6 & Snacks-Produce & $33.78 \%$ & $77 \%$ \\
7 & Frozen-Dairy eggs & $30.05 \%$ & $77 \%$ \\
8 & Pets-Dairy eggs & $1.44 \%$ & $69 \%$ \\
9 & Household-Produce & $11.14 \%$ & $57 \%$ \\
10 & Breakfast-Snacks & $10.28 \%$ & $61 \%$ \\
11 & Pets-Beverages & $1.25 \%$ & $60 \%$ \\
12 & International-Pantry & $4.20 \%$ & $56 \%$ \\
13 & Dry goods and Pasta-Frozen & $10.99 \%$ & $55 \%$ \\
14 & Bakery-Snacks & $15.25 \%$ & $55 \%$ \\
15 & Babies-Frozen & $2.57 \%$ & $52 \%$ \\
16 & Deli-Beverages & $12.93 \%$ & $52 \%$ \\
17 & Meat Seafood-Pantry & $8.97 \%$ & $48 \%$ \\
18 & International-Canned goods & $3.17 \%$ & $42 \%$ \\
19 & Deli-Bakery & $10.02 \%$ & $40 \%$ \\
20 & Dry goods and Pasta-Canned goods & $7.95 \%$ & $40 \%$ \\
\hline
\end{tabular}

\subsection{Adjacency Preferences}

One of the most widely used approaches for measuring the effectiveness of the shelf layout problem is the REL chart $[75,76]$, which determines closeness ratings. A closeness rating reflects the correlation between shelves. Here, the proximity rating was defined as shown in Table 9, and an adjacency matrix (defined from the valuable rack pair) was created to determine the suitability of a shelf location. We used the PrefixSpan algorithm to match shelf correlations, support, and confidence, as shown in Table 8, where rack correlation pairs with a confidence value of greater than $60 \%$, between 60 and $40 \%$, between 40 and $20 \%$, and between 20 and $10 \%$ are considered "Absolutely necessary", "Especially important", "Important", and "Ordinary closeness", respectively. The generated adjacency matrix is displayed in Table 10. Because shelf layout directly affects the sales of products, the adjacency matrix is used to measure the effectiveness of a shelf layout when in the process of determining proximity values. Proximity values alone should not be used to calculate the income or profit of a shelf; adjacency preferences should also be considered.

Table 9. REL score chart.

\begin{tabular}{ccc}
\hline Rating & Definition & Assigned Score \\
\hline A & Absolutely necessary & 125 \\
E & Especially important & 25 \\
I & Important & 5 \\
O & Ordinary closeness & 0 \\
U & Unimportant & -25 \\
X & Undesirable & -125 \\
\hline
\end{tabular}


Table 10. Adjacency matrix.

\begin{tabular}{|c|c|c|c|c|c|c|c|c|c|c|c|c|c|c|c|c|c|c|c|}
\hline Department & 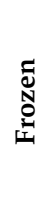 & $\frac{\vec{D}}{\stackrel{\Delta}{\pi}}$ & 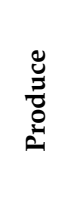 & $\begin{array}{l}\overline{0} \\
\frac{1}{0} \\
\frac{0}{4}\end{array}$ & 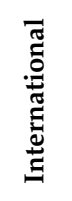 & 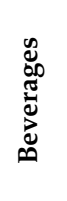 & $\stackrel{n}{\mathscr{L}}$ & $\begin{array}{l}\text { के } \\
8 \\
0 \\
0 \\
0 \\
0\end{array}$ & 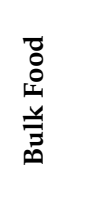 & 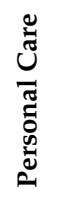 & 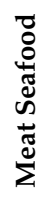 & $\underset{\text { E }}{\stackrel{\text { E }}{E}}$ & 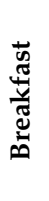 & 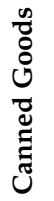 & 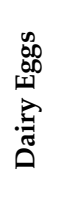 & 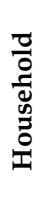 & $\frac{\mathscr{0}}{\frac{0}{0}}$ & 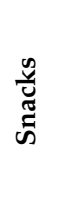 & อ̈ \\
\hline Frozen & 0 & 5 & 125 & -25 & 0 & 25 & -25 & 5 & -25 & 0 & 5 & 25 & 5 & 5 & 125 & 0 & -25 & 25 & 5 \\
\hline Bakery & 25 & 0 & 125 & -25 & 0 & 25 & -25 & 5 & -25 & 0 & 5 & 25 & 5 & 5 & 125 & 0 & -25 & 25 & 5 \\
\hline Produce & 25 & 5 & 0 & -25 & -25 & 25 & -25 & 5 & -25 & 0 & 5 & 25 & 0 & 5 & 125 & 0 & -25 & 25 & 5 \\
\hline Alcohol & 5 & 5 & 25 & 0 & -25 & 25 & -25 & 0 & -125 & 0 & 0 & 5 & 0 & 0 & 25 & 5 & -25 & 5 & 0 \\
\hline International & 25 & 5 & 125 & -25 & 0 & 25 & -25 & 5 & -25 & 0 & 5 & 25 & 5 & 25 & 125 & 0 & -25 & 25 & 5 \\
\hline Beverages & 25 & 5 & 125 & -25 & -25 & 0 & -25 & 5 & -25 & 0 & 0 & 5 & 0 & 5 & 125 & 5 & -25 & 25 & 5 \\
\hline Pets & 25 & 5 & 125 & -25 & -25 & 125 & 0 & 5 & -125 & 5 & 5 & 25 & 5 & 5 & 125 & 5 & -25 & 25 & 5 \\
\hline Dry goods & 25 & 25 & 125 & -25 & 0 & 25 & -25 & 0 & -25 & 0 & 5 & 25 & 5 & 25 & 125 & 0 & -25 & 25 & 5 \\
\hline Bulk food & 25 & 5 & 125 & -125 & -25 & 25 & -125 & 5 & 0 & -25 & 5 & 25 & 5 & 5 & 125 & 0 & -25 & 25 & 5 \\
\hline Personal care & 25 & 5 & 125 & -25 & -25 & 25 & -25 & 5 & -125 & 0 & 0 & 25 & 5 & 5 & 125 & 5 & -25 & 25 & 5 \\
\hline Meat Seafood & 25 & 5 & 125 & -25 & 0 & 25 & -25 & 5 & -25 & 0 & 0 & 25 & 5 & 5 & 125 & 0 & -25 & 25 & 5 \\
\hline Pantry & 25 & 5 & 125 & -25 & 0 & 25 & -25 & 5 & -25 & 0 & 5 & 0 & 5 & 5 & 125 & 0 & -25 & 25 & 5 \\
\hline Breakfast & 25 & 25 & 125 & -25 & -25 & 25 & -25 & 5 & -25 & 0 & 5 & 25 & 0 & 5 & 125 & 5 & -25 & 125 & 5 \\
\hline Canned goods & 25 & 5 & 125 & -25 & 0 & 25 & -25 & 5 & -25 & 0 & 5 & 25 & 5 & 0 & 125 & 0 & -25 & 25 & 5 \\
\hline Dairy eggs & 25 & 5 & 125 & -25 & -25 & 25 & -25 & 5 & -25 & 0 & 5 & 25 & 5 & 5 & 0 & 0 & -25 & 25 & 5 \\
\hline Household & 25 & 5 & 125 & -25 & -25 & 25 & -25 & 5 & -125 & 5 & 5 & 25 & 5 & 5 & 125 & 0 & -25 & 25 & 5 \\
\hline Babies & 25 & 5 & 125 & -25 & -25 & 25 & -25 & 5 & -25 & 0 & 5 & 25 & 5 & 5 & 125 & 5 & 0 & 25 & 5 \\
\hline Snacks & 25 & 5 & 125 & -25 & -25 & 25 & -25 & 5 & -25 & 0 & 5 & 25 & 5 & 5 & 125 & 0 & -25 & 0 & 5 \\
\hline Deli & 25 & 25 & 125 & -25 & 0 & 25 & -25 & 5 & -25 & 0 & 5 & 25 & 5 & 5 & 125 & 0 & -25 & 25 & 0 \\
\hline
\end{tabular}

\subsection{Multi-Objective Mutation-Based Harmony Search for Layout Design}

We propose the use of the MBHS algorithm to manage shelf layouts for maximum improvements of profitability and closeness ratings. Figure 2 illustrates the procedures of MBHS.

The profit measure equation, shown in Equation (3), was used in this study to identify correlations between shelves to compare profitability between the case supermarket's traditional shelf layouts and those of our proposed method:

$$
\text { Profit function }=\left\{\begin{array}{c}
\max f\left(X_{i}\right), \\
f\left(X_{i}\right)=\frac{\sum_{i=1}^{n-1} \sum_{j=j+1}^{n}\left(P_{i j}\right) \times \sigma\left(\frac{D_{i} \cup D_{j}}{|T|}\right)}{L}
\end{array}\right.
$$

where $P$ represents the profit value of the pattern, $n$ represents the number of departments, $\sigma$ represents the fraction of transactions that contains both $i$ and $j, \mathrm{~T}$ represents the total number of transactions, and $\mathrm{L}$ represents the length of the pattern.

Equation (4) was used to calculate the total closeness rating (TCR) to measure the overall effectiveness of the correlation between shelves of the supermarket:

$$
\mathrm{TCR} \text { function }=\sum_{i=1}^{n-1} \sum_{j=j+1}^{n}\left(R E L_{i j}\right)
$$

where REL represents the assigned scores of patterns from department $i$ to $j$ and $n$ represents the number of departments. 


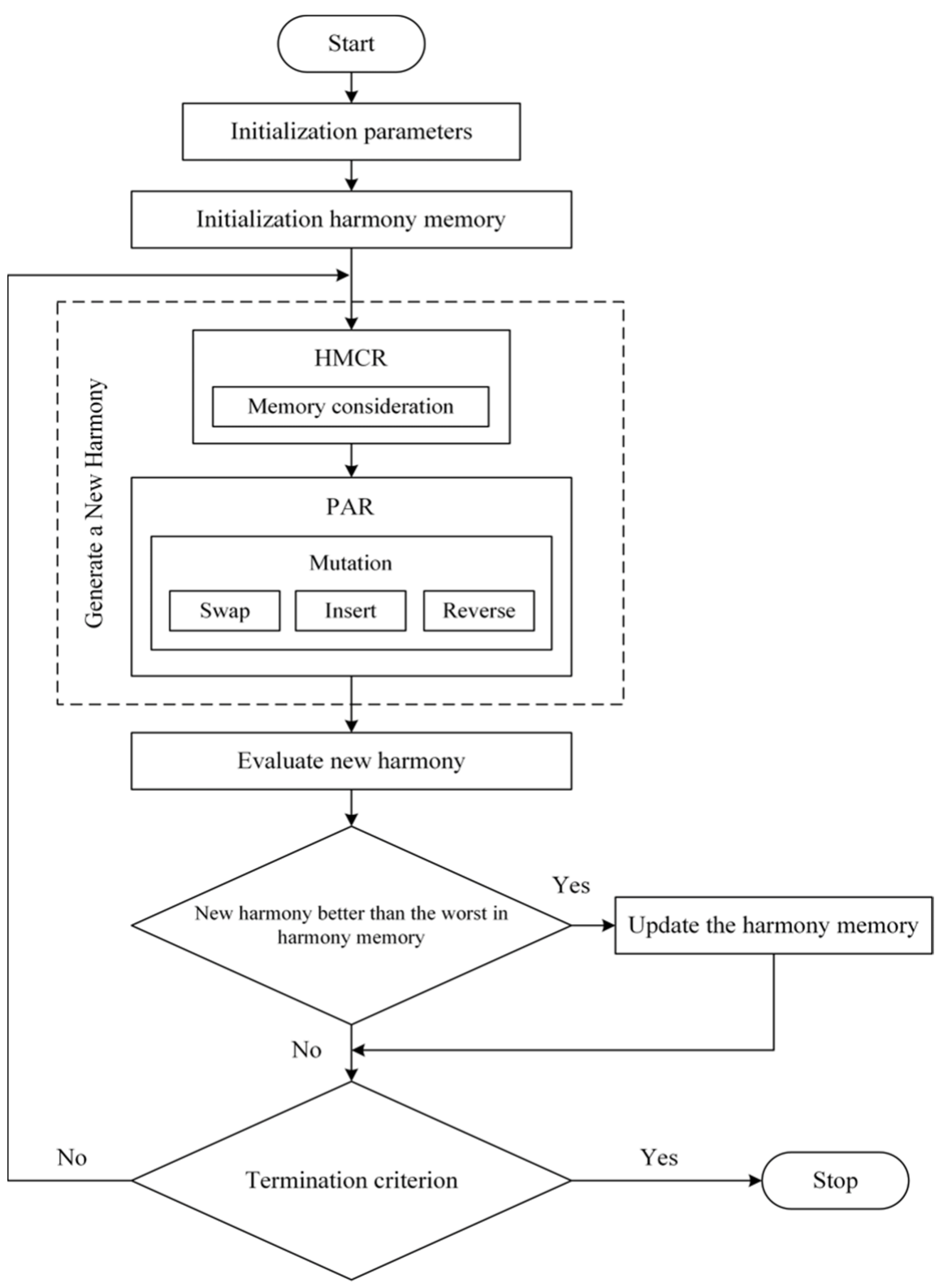

Figure 2. Mutation-based harmony search algorithm.

\subsubsection{Initialization Parameters and the Harmony Memory}

First, we configured the parameters with the harmony memory size (HMS), harmony memory consideration rate (HMCR), pitch adjusting rate (PAR), and termination criterion (e.g., maximum number of iterations). Then, the product shelves were randomized to generate a $1 \times 19$ initial population matrix, with $n$ numbers defined by HMS values. The generated population was stored in the harmony memory (HM) and then evaluated according to Equations (3) and (4). The initial population model is displayed in Equation (5):

$$
H M=\left[\begin{array}{cccccc}
X_{1}^{1} & X_{2}^{1} & \cdots & X_{n}^{1} & f\left(X^{1}\right) & T C R^{1} \\
X_{1}^{2} & X_{2}^{2} & \cdots & X_{n}^{2} & f\left(X^{2}\right) & T C R^{2} \\
\vdots & \vdots & \cdots & \vdots & \vdots & \vdots \\
X_{1}^{H M S} & X_{2}^{H M S} & \cdots & X_{1}^{H M S} & f\left(X^{H M S}\right) & T C R^{H M S}
\end{array}\right]
$$




\subsubsection{Generating a New Harmony}

At this stage, a new harmony was created based on $X^{\text {new }}=\left[X_{1}^{\text {new }}, X_{2}^{\text {new }}, \cdots, X_{n}^{\text {new }}\right]$ by considering the HMCR value, which was a randomized number between 0 and 1 . If it was less than or equal to the HMCR, it generated a new harmony from the HM. Then, the new harmony was randomized. The next step decided whether to again perform the PAR procedure randomly from 0 to 1 . If the value was found to be less than or equal to the specified PAR, mutation operations were implemented. We used three types of operators to find the location closest to the answer: (a) the swap operator, which selects random shelf and swap positions; (b) the insert operator, which randomly selects two shelf positions and inserts the first position into the front; and (c) the reverse operator, which randomly selects the order of the shelf's length and then reverses it. The three mutation operators are illustrated in Figure 3.

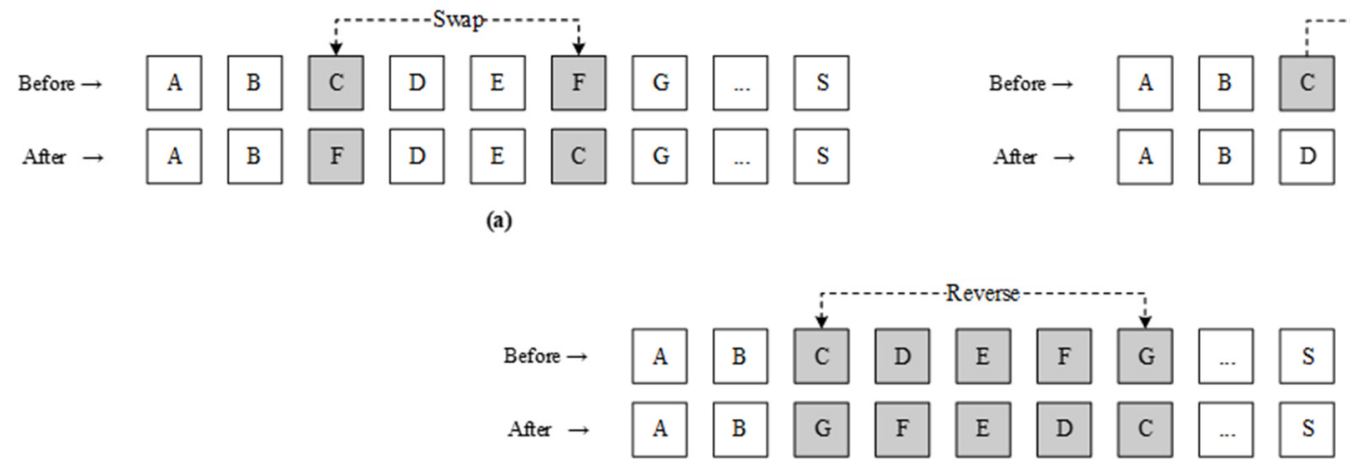

(c)

Figure 3. Mutation operation: (a) swap operator, (b) insert operator and (c) reverse operator.

\subsubsection{Update the Harmony Memory}

At this stage, Xnew was compared to Xworst in the HM. If the new harmony, Xnew, had better suitability, Xworst in the HM replaced the position with Xnew.

\subsubsection{Terminate Criterion}

In this step, the procedure for generating and updating a new harmony memory was repeated until the specified number of rounds was completed, at which point the algorithm had found the best suitability.

\section{Experiments and Results}

\subsection{Multi-Objective Evaluation}

In this research, we applied a multi-objective mutation-based harmony search algorithm to handle large shelf data. In the database, there were 1,048,576 purchase sale records, 19 shelf records, and 49,688 product records. Figure 4a shows the original product layout, and Table 12 shows the proposed product layout with shelf improvements. This layout was developed with the experimental results by using the profit volume calculated from Equation (3) and finding the suitability of the closeness rating. Table 11 shows the profit volume values following shelf adjustment, which were calculated by determining the solution of a rack from 19 departments. The solution comprised a $1 \times 19$ matrix, with the best answer determined by the highest profit sum and the TCR determined by the original product layout (as illustrated in Figure 4a). The proposed product layout is shown in Figure $4 \mathrm{~b}$. According to the results of the experiment, the improvements of the proposed and conventional shelf layouts had profit volume values of 228,139.50 (THB) and 441,477.71 (THB), respectively, as shown in Table 12. 


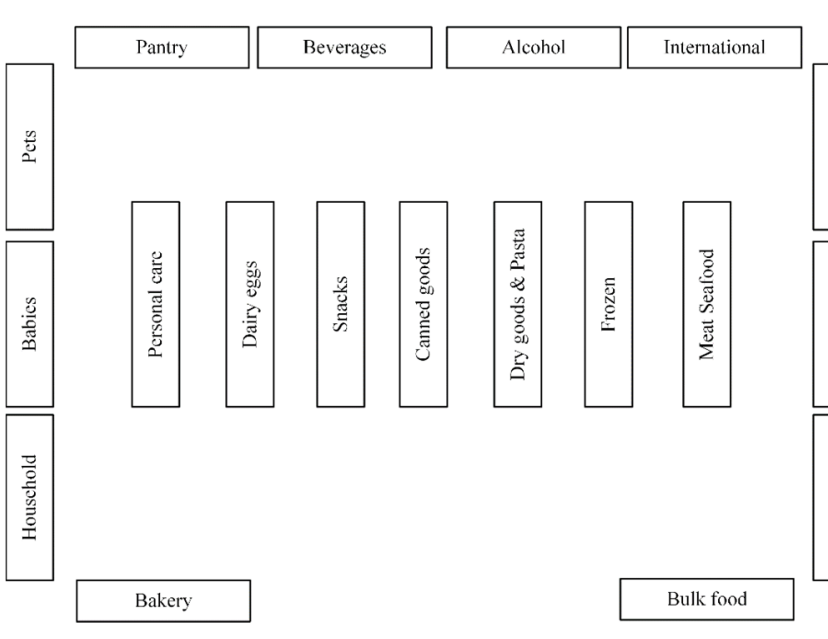

(a)

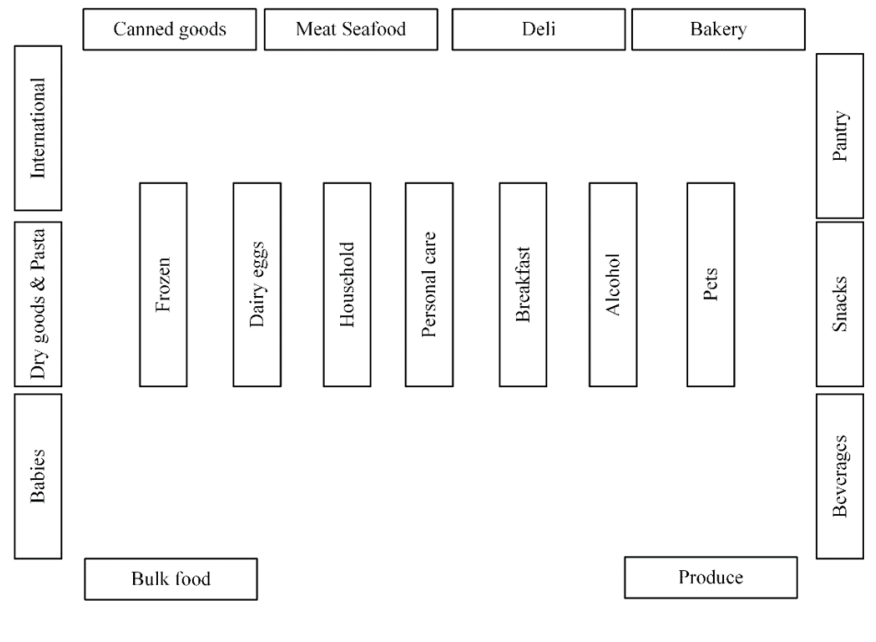

(b)

Figure 4. Product layouts: (a) the original product layout; (b) the proposed product layout.

Table 11. Profit volumes, total closeness rating, and execution time for the three algorithms.

\begin{tabular}{|c|c|c|c|c|c|c|c|c|c|}
\hline \multirow{2}{*}{ Iteration } & \multicolumn{3}{|c|}{ PrefixSpan and MBHS(Proposed Algorithm) } & \multicolumn{3}{|c|}{ GA } & \multicolumn{3}{|c|}{ SA } \\
\hline & Profit & TCR & Time(s) & Profit & TCR & Time(s) & Profit & TCR & Time(s) \\
\hline 1 & $311,235.91$ & 105 & 0.03 & $255,865.51$ & -5 & 3.82 & $249,138.03$ & 225 & 0.008 \\
\hline 25 & $390,576.34$ & 205 & 0.46 & $367,919.9$ & 10 & 9.62 & $307,112.12$ & 285 & 0.026 \\
\hline 50 & $396,787.27$ & 180 & 0.84 & $372,192.96$ & 35 & 13.38 & $324,907.14$ & 160 & 0.031 \\
\hline 75 & $416,880.68$ & 205 & 1.32 & $390,894.29$ & 100 & 17.23 & $321,803.74$ & 305 & 0.036 \\
\hline 100 & $433,363.4$ & 210 & 1.69 & $390,894.29$ & 100 & 20.37 & $341,573.87$ & 275 & 0.042 \\
\hline 150 & $441,331.74$ & 345 & 2.80 & $392,172.53$ & 150 & 26.68 & $341,573.87$ & 275 & 0.052 \\
\hline 180 & $441,477.71$ & 350 & 3.12 & $392,172.53$ & 150 & 30.05 & $341,573.87$ & 275 & 0.058 \\
\hline 190 & $441,477.71$ & 350 & 3.21 & $392,172.53$ & 150 & 31.17 & $341,573.87$ & 275 & 0.060 \\
\hline 200 & $441,477.71$ & 350 & 3.55 & $392,172.53$ & 150 & 32.29 & $341,573.87$ & 275 & 0.062 \\
\hline
\end{tabular}

Table 12. Comparison of the profit volume and total closeness rating.

\begin{tabular}{ccc}
\hline & Profit Volume (THB) & Total Closeness Rating \\
\hline Original layout & $228,139.50$ & 205 \\
Proposed layout & $441,477.71$ & 350 \\
\hline
\end{tabular}

Table 12 presents the sum of the total closeness ratings. The results show that the original product layout had a TCR of 205, but the proposed product layout had a TCR of 350. In other words, the proposed method provided a higher profit volume and a better TCR value. This new shelf layout was additionally determined to be able to lead to an increase in customer satisfaction levels. In summary, the proposed method can effectively improve the placement of store shelves and increase future sales by using correlations between shopping lists and shelf layouts.

\subsection{Comparison of Algorithms}

In this experiment, we evaluated the execution time of the Apriori algorithm, the FP-Growth algorithm, and the proposed PrefixSpan algorithm on the same large dataset, as shown in Table 13. 
Table 13. Comparison of the execution time of Apriori, FP-Growth, and Prefixspan.

\begin{tabular}{cc}
\hline Algorithms & Execute Times (Second) \\
\hline Apriori & 715.51 \\
FP-Growth & 92.18 \\
Prefixspan & 0.29 \\
\hline
\end{tabular}

Table 13 displays a comparison of the time needed by the Apriori, FP-Growth, and PrefixSpan algorithms to correlate all occurring rules using the same dataset. We set a minimum support value of $1 \%$. The PrefixSpan algorithm performed better than the other algorithms. The average execution times of the Apriori, FP-Growth, and PrefixSpan algorithms were 1411.02, 279.37, and 30.27 s, respectively.

Figure 5 shows a comparison of the execution times of the Apriori, FP-Growth, and PrefixSpan algorithms with minimum supports of $20 \%, 40 \%, 60 \%$, and $80 \%$. According to the time processing results shown in Figure 5, at the minimum support of $20 \%$, the average execution times of the Apriori, FP-Growth, and PrefixSpan algorithms were 715.51, 92.18 , and $1.67 \mathrm{~s}$, respectively. At the minimum support of $80 \%$, the average execution times of the Apriori, FP-Growth, and PrefixSpan algorithms were 73.40, 11.15, and $0.29 \mathrm{~s}$, respectively. It was found that the execution time depended on the minimum support setting. If the minimum support was smaller, the processing time was longer, and the resulting correlation rule was more common. Table 13 shows that the execution time of the PrefixSpan algorithm was better than those of the Apriori and FP-Growth algorithms.

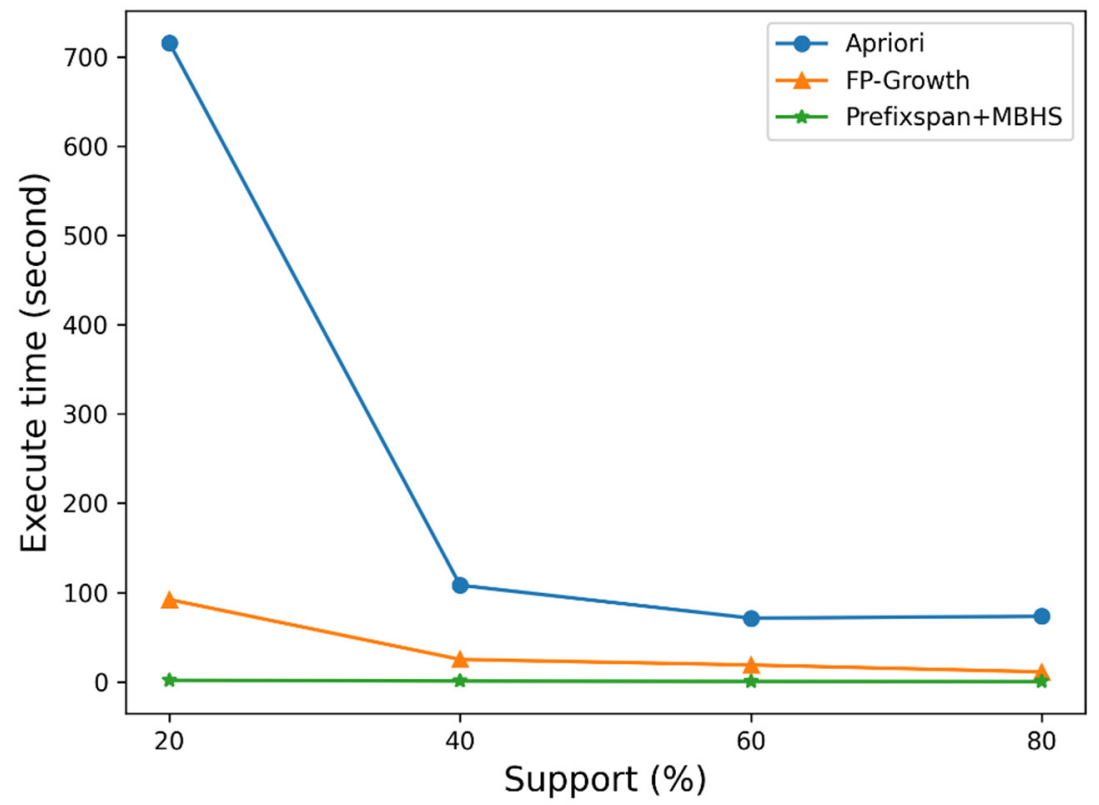

Figure 5. Comparison of the execution times of the Apriori, FP-Growth, and PrefixSpan algorithms according to the percent of support.

The four algorithms were executed in the same environment after setting the following hyperparameters: the PrefixSpan and MBHS settings were HMS $=25, \mathrm{HMCR}=0.9$, and $\mathrm{PAR}=0.1$; the SA settings were initial temperature $=100$, cooling rate $=0.99$, and complete temperature $=0.01$; and the GA settings were initial population size $=2000$, $\mathrm{pc}=0.2$, $\mathrm{pm}=0.08$, and iteration $=200$. Table 14 shows the experimentally finetuned parameters . 
Table 14. The hyperparameters of the selected algorithms.

\begin{tabular}{ccc}
\hline Algorithm & Parameter & Selected Values \\
\hline \multirow{3}{*}{ PrefixSpan and MBHS } & HMS & 25 \\
& HMCR & 0.9 \\
& PAR & 0.1 \\
SA & Initial temperature & 100 \\
& Cooling rate & 0.99 \\
& Complete temperature & 0.01 \\
GA & Population size & 2000 \\
& Probability of crossover: Pc & 0.2 \\
& Probability of mutation: Pm & 0.08 \\
& Iteration & 200 \\
\hline
\end{tabular}

\subsection{Discussion}

To discuss the experiment, the PrefixSpan and MBHS, GA, and SA were applied to shelf layouts to evaluate profit and time consumption. Figure 6 shows a comparison of the profit volume and execution time as the number of iterations increased: Figure 6a profit volume of the algorithms and Figure $6 \mathrm{~b}$ execution time of the algorithms. A comparison of the profit volume of the proposed method (PrefixSpan and MBHS), GA, and SA, respectively, were given the highest profit and convergence to the best answer when the number of iterations was higher. Comparison with the other algorithms shows convergence and stability within 100 iterations, which was less profit than the proposed model. In contrast, the aspect of the time consumption of the proposed and SA was similar within 50 iterations. The GA and NP-Hard dramatically increased until 200 iterations. The processing time of NP-Hard was longer when the number of iterations was higher. The product layout profitability, total closeness rating, and execution time of the three algorithms, proposed method as the PrefixSpan algorithm with mutation-based harmony search (PrefixSpan and MBHS), the GA, and the SA, respectively, were employed. Table 11 (where the yand $\mathrm{x}$-axes are the sum of the profit of the product layout and the cycle of the execution of each algorithm, respectively) shows a comparison of the profitability and reveals the best answer. Figure 6a shows the PrefixSpan and MBHS algorithms were better able to determine the suitability or profit of the product layout than the other two algorithms. A new multi-objective design was included to filter both the profit and closeness rating into unique functions in the search space. In addition, the PrefixSpan and MBHS algorithm showed the highest performance and enhance aspect in the other performance comparison. Therefore, the PrefixSpan and MBHS in Figure $6 \mathrm{~b}$ show that among the algorithms, the GA and the SA were the most and least time-consuming, respectively. Regarding the number of NP-hard, the number of profits of the product layout is the least time-consuming, grew very rapidly even in the case of small-size products, and was unable to be solved when the iteration increased to the MBHS algorithm when it included the PrefixSpan algorithm to solve the initial set of the population in the heuristic search before reaching the search space. Moreover, the time consumption was reduced compared to others. SA was the worst-performing algorithm because the SA has the disadvantage of huge items, and the algorithm can be across the best answer because GA and SA are an initial set of random answers. Therefore, it can be concluded that the proposed multi-objective mutation-based harmony search algorithm was the most efficient one of the tested algorithms. 


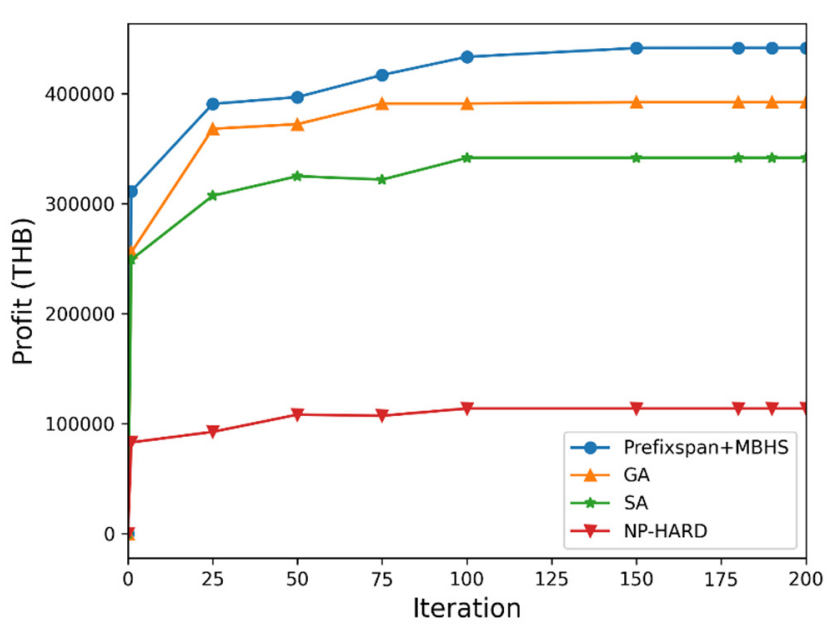

(a)

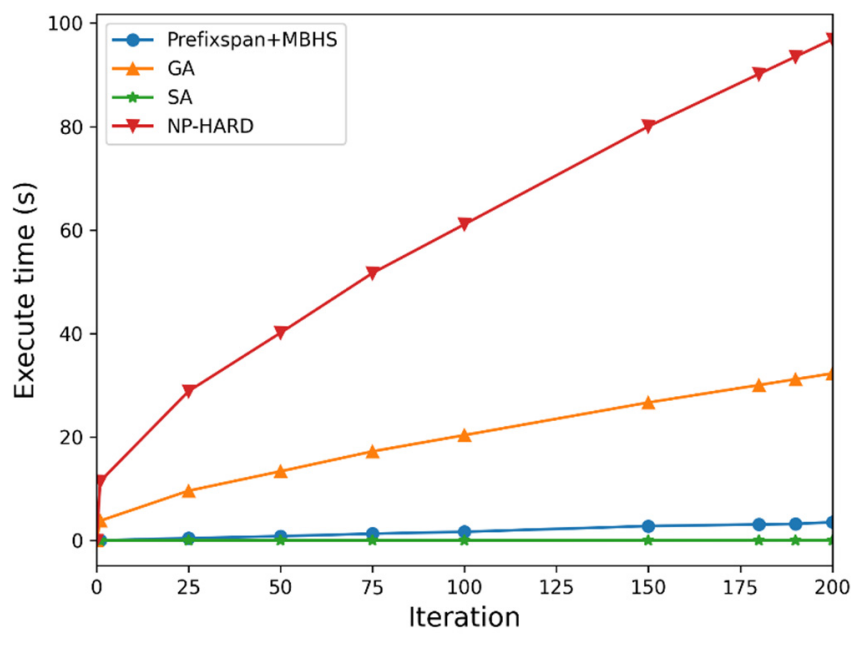

(b)

Figure 6. Comparison of the profit volume and execution time as the number of iterations increased: (a) profit volume of the algorithms; (b) execution time of the algorithms.

\section{Conclusions and Future Work}

We proposed the use of a PrefixSpan mining approach in conjunction with MBHS to identify sequential patterns in customer purchase data. Our experimental results revealed that the proposed method can rearrange product layouts by analyzing customers' shopping lists. This method was found to lead to increased profitability, higher total closeness ratings, and more efficient execution times compared with those of the original product layout. The proposed method was also found to be more effective than other comparable approaches as well as to be suitable for multi-objective pattern optimization in supermarkets regarding profit, closeness ratio, and consumer time efficiency. In future work, we will improve our multi-objective functions by using machine learning and developing a heuristic mining approach for the optimal solution.

Author Contributions: Conceptualization, J.K. and W.S.; methodology, J.K. and W.S.; software, J.K. and W.S.; validation, J.K. and W.S.; formal analysis, J.K. and W.S.; investigation, J.K. and W.S.; resources, J.K. and W.S.; writing — original draft preparation, J.K.; writing —review and editing, J.K. and W.S.; project administration, W.S. All authors have read and agreed to the published version of the manuscript.

Funding: This research received no external funding.

Institutional Review Board Statement: Not applicable.

Informed Consent Statement: Not applicable.

Data Availability Statement: Not applicable.

Acknowledgments: This research was financially supported in part by the researcher development project of the Department of Computer Science, Faculty of Science, Khon Kaen University, Thailand.

Conflicts of Interest: The authors declare no conflict of interest.

\section{References}

1. Agrawal, R.; Srikant, R. Mining Sequential Patterns. In Proceedings of the Eleventh International Conference on Data Engineering, Washington, DC, USA, 6-10 March 1995; pp. 3-14.

2. Srikant, R.; Agrawal, R. Mining Sequential Patterns: Generalizations and Performance Improvements. In Advances in Database Technology, Proceedings of the International Conference on Extending Database Technology EDBT '96, Munich, Germany, 26-31 March 2006; Apers, P., Bouzeghoub, M., Gardarin, G., Eds.; Springer: Berlin/Heidelberg, 1996; pp. 1-17.

3. Han, J.; Pei, J.; Kamber, M. Data Mining: Concepts and Techniques, 3rd ed.; Morgan Kaufmann: Waltham, MA, USA, 2011. 
4. Tsai, C.; Wu, M. Applying a Two-Stage Simulated Annealing Algorithm for Shelf Space Allocation Problems. In Proceedings of the World Congress on Engineering, London, UK, 30 June-2 July 2010; Volume 30, pp. 2376-2380.

5. Lu, Y.; Seo, H.-B. Developing Visibility Analysis for a Retail Store: A Pilot Study in a Bookstore. Environ. Plan. B Plan. Des. 2015, 42, 95-109. [CrossRef]

6. Guidotti, R.; Rossetti, G.; Pappalardo, L.; Giannotti, F.; Pedreschi, D. Personalized Market Basket Prediction with Temporal Annotated Recurring Sequences. IEEE Trans. Knowl. Data Eng. 2019, 31, 2151-2163. [CrossRef]

7. Kanavos, A.; Iakovou, S.A.; Sioutas, S.; Tampakas, V. Large Scale Product Recommendation of Supermarket Ware Based on Customer Behaviour Analysis. Big Data Cogn. Comput. 2018, 2, 11. [CrossRef]

8. Seraphim, B.I.; Rao, L.S.; Joshi, S. Survey on Customer Centric Sales Analysis and Prediction. In Proceedings of the 2018 3rd International Conference on Inventive Computation Technologies (ICICT), Coimbatore, India, 15-16 November 2018; pp. 495-500.

9. Yuan, X.; Chang, W.; Zhou, S.; Cheng, Y. Sequential Pattern Mining Algorithm Based on Text Data: Taking the Fault Text Records as an Example. Sustainability 2018, 10, 4330. [CrossRef]

10. Valle, M.A.; Ruz, G.A.; Morrás, R. Market Basket Analysis: Complementing Association Rules with Minimum Spanning Trees. Expert Syst. Appl. 2018, 97, 146-162. [CrossRef]

11. Kanaan, M.; Cazabet, R.; Kheddouci, H. Temporal Pattern Mining for E-commerce Dataset. In Transactions on Large-Scale Data- and Knowledge-Centered Systems XLVI; Hameurlain, A., Tjoa, A.M., Eds.; Lecture Notes in Computer Science; Springer: Berlin/Heidelberg, Germany, 2020; pp. 67-90. ISBN 978-3-662-62386-2.

12. González, E.M.; Meyer, J.-H.; Paz Toldos, M. What Women Want? How Contextual Product Displays Influence Women's Online Shopping Behavior. J. Bus. Res. 2021, 123, 625-641. [CrossRef]

13. Wang, H.; Du, Y.; Yi, J.; Wang, N.; Liang, F. Mining Evolution Patterns from Complex Trajectory Structures-A Case Study of Mesoscale Eddies in the South China Sea. ISPRS Int. J. Geo-Inf. 2020, 9, 441. [CrossRef]

14. Haritha, P.; Sreedevi, M.; Ravali, K.; ManojPruthvi, M. A Survey for Acquiring Frequent and Sequential Items in E-Commerce Sites. Int. J. Eng. Technol. 2017, 7, 273-277. [CrossRef]

15. Chen, Y.-L.; Chen, J.-M.; Tung, C.-W. A Data Mining Approach for Retail Knowledge Discovery with Consideration of the Effect of Shelf-Space Adjacency on Sales. Decis. Support Syst. 2006, 42, 1503-1520. [CrossRef]

16. Zhou, H.; Hirasawa, K. Evolving Temporal Association Rules in Recommender System. Neural Comput. Appl. 2019, 31, 2605-2619. [CrossRef]

17. Kim, G.; Moon, I. Integrated Planning for Product Selection, Shelf-Space Allocation, and Replenishment Decision with Elasticity and Positioning Effects. J. Retail. Consum. Serv. 2021, 58, 102274. [CrossRef]

18. Sowmyanarayanan, R.; Krishnaa, G.; Gupta, D. Beyond Kirana Stores: A Study on Consumer Purchase Intention for Buying Grocery Online. In ICTIS 2020: Information and Communication Technology for Intelligent Systems, Proceedings of the International Conference on Information and Communication Technology for Intelligent Systems, Ahmedabad, India, 15-16 May 2020; Springer: Berlin/Heidelberg, Germany, 2020; pp. 599-606.

19. Chen, Y.-L.; Tang, K.; Shen, R.-J.; Hu, Y.-H. Market Basket Analysis in a Multiple Store Environment. Decis. Support Syst. 2005, 40, 339-354. [CrossRef]

20. Borgelt, C. Frequent Item Set Mining. WIREs Data Min. Knowl. Discov. 2012, 2, 437-456. [CrossRef]

21. Finamore, A.C.; Jiménez, H.G.; Casanova, M.A.; Nunes, B.P.; Santos, A.M.; Pires, A.P. A Comparative Analysis of Two Computer Science Degree Offerings. J. Braz. Comput. Soc. 2020, 26, 1-23. [CrossRef]

22. Mild, A.; Reutterer, T. An Improved Collaborative Filtering Approach for Predicting Cross-Category Purchases Based on Binary Market Basket Data. J. Retail. Consum. Serv. 2003, 10, 123-133. [CrossRef]

23. Verma, N.; Malhotra, D.; Singh, J. Big Data Analytics for Retail Industry Using MapReduce-Apriori Framework. J. Manag. Anal. 2020, 7, 424-442. [CrossRef]

24. Li, H.; Wu, Y.J.; Chen, Y. Time Is Money: Dynamic-Model-Based Time Series Data-Mining for Correlation Analysis of Commodity Sales. J. Comput. Appl. Math. 2020, 370, 112659. [CrossRef]

25. Wang, F.; Wen, Y.; Guo, T.; Liu, J.; Cao, B. Collaborative Filtering and Association Rule Mining-Based Market Basket Recommendation on Spark. Concurr. Comput. Pract. Exp. 2020, 32, e5565. [CrossRef]

26. Ünvan, Y.A. Market Basket Analysis with Association Rules. Commun. Stat. Theory Methods 2020, 50, 1615-1628. [CrossRef]

27. Qu, J.-F.; Fournier-Viger, P.; Liu, M.; Hang, B.; Wang, F. Mining High Utility Itemsets Using Extended Chain Structure and Utility Machine. Knowl. Based Syst. 2020, 208, 106457. [CrossRef]

28. Raeder, T.; Chawla, N.V. Market Basket Analysis with Networks. Soc. Netw. Anal. Min. 2011, 1, 97-113. [CrossRef]

29. Reyes, P.M.; Frazier, G.V. Goal Programming Model for Grocery Shelf Space Allocation. Eur. J. Oper. Res. 2007, 181, 634-644. [CrossRef]

30. Inglay, R.; Dhalla, R. Application of Systematic Layout Planning in Hypermarkets. In Proceedings of the 2010 International Conference on Industrial Engineering and Operations Management, Dhaka, Bangladesh, 9-10 January 2010; pp. 9-10.

31. Brandtner, P.; Darbanian, F.; Falatouri, T.; Udokwu, C. Impact of COVID-19 on the Customer End of Retail Supply Chains: A Big Data Analysis of Consumer Satisfaction. Sustainability 2021, 13, 1464. [CrossRef]

32. Jian, P.; Jiawei, H.; Mortazavi-Asl, B.; Pinto, H.; Qiming, C.; Dayal, U.; Mei-Chun, H. PrefixSpan: Mining Sequential Patterns Efficiently by Prefix-Projected Pattern Growth. In Proceedings of the 17th International Conference on Data Engineering, Heidelberg, Germany, 2-6 April 2001; pp. 215-224. 
33. Wang, J.; Han, J. BIDE: Efficient Mining of Frequent Closed Sequences. In Proceedings of the 20th International Conference on Data Engineering, Boston, MA, USA, 2nd April 2004; pp. 79-90.

34. Gao, C.; Wang, J.; He, Y.; Zhou, L. Efficient Mining of Frequent Sequence Generators. In WWW'08: Proceedings of the 17th International Conference on World Wide Web, Beijing, China 21-25 April 2008; Association for Computing Machinery: New York, NY, USA, 2008; pp. 1051-1052.

35. Çetin, O.; Mersereau, A.J.; Parlaktürk, A.K. Management and Effects of In-Store Promotional Displays. Manuf. Serv. Oper. Manag. 2019, 22, 481-494. [CrossRef]

36. Chaudhary, P.; Mondal, A.; Reddy, P.K. An Improved Scheme for Determining Top-Revenue Itemsets for Placement in Retail Businesses. Int. J. Data Sci. Anal. 2020, 10, 359-375. [CrossRef]

37. Wang, X.; Wang, F.; Yan, S.; Liu, Z. Application of Sequential Pattern Mining Algorithm in Commodity Management. J. Electron. Commer. Organ. 2018, 16, 94-106. [CrossRef]

38. Timonina-Farkas, A.; Katsifou, A.; Seifert, R.W. Product Assortment and Space Allocation Strategies to Attract Loyal and Non-Loyal Customers. Eur. J. Oper. Res. 2020, 285, 1058-1076. [CrossRef]

39. Goldberg, D.E. Genetic Algorithms in Search, Optimization and Machine Learning, 1st ed.; Addison-Wesley Longman Publishing Co., Inc.: Boston, MA, USA, 1989; ISBN 0-201-15767-5.

40. Bonyadi, M.R.; Michalewicz, Z. Particle Swarm Optimization for Single Objective Continuous Space Problems: A Review. Evol. Comput. 2017, 25, 1-54. [CrossRef]

41. Kong, L.; Wang, J.; Zhao, P. Solving the Dynamic Weapon Target Assignment Problem by an Improved Multiobjective Particle Swarm Optimization Algorithm. Appl. Sci. 2021, 11, 9254. [CrossRef]

42. Kirkpatrick, S.; Gelatt, C.D.; Vecchi, M.P. Optimization by Simulated Annealing. Science 1983, 220, 671-680. [CrossRef] [PubMed]

43. Roeva, O.; Zoteva, D.; Lyubenova, V. Escherichia Coli Cultivation Process Modelling Using ABC-GA Hybrid Algorithm. Processes 2021, 9, 1418. [CrossRef]

44. Villegas, J.M.; Caraveo, C.; Mejía, D.A.; Rodríguez, J.L.; Vega, Y.; Cervantes, L.; Medina-Santiago, A. Intelligent Search of Values for a Controller Using the Artificial Bee Colony Algorithm to Control the Velocity of Displacement of a Robot. Algorithms 2021, 14, 273. [CrossRef]

45. Geem, Z.W.; Kim, J.H.; Loganathan, G.V. A New Heuristic Optimization Algorithm: Harmony Search. SIMULATION 2001, 76, 60-68. [CrossRef]

46. Peraza, C.; Valdez, F.; Castillo, O. A harmony search algorithm comparison with genetic algorithms. In Fuzzy Logic Augmentation of Nature-Inspired Optimization Metaheuristics; Springer: Berlin/Heidelberg, Germany, 2015; pp. 105-123.

47. Lee, K.S.; Geem, Z.W. A New Structural Optimization Method Based on the Harmony Search Algorithm. Comput. Struct. 2004, 82, 781-798. [CrossRef]

48. Lee, K.S.; Geem, Z.W. A New Meta-Heuristic Algorithm for Continuous Engineering Optimization: Harmony Search Theory and Practice. Comput. Methods Appl. Mech. Eng. 2005, 194, 3902-3933. [CrossRef]

49. Mahdavi, M.; Fesanghary, M.; Damangir, E. An Improved Harmony Search Algorithm for Solving Optimization Problems. Appl. Math. Comput. 2007, 188, 1567-1579. [CrossRef]

50. Szwarc, K.; Boryczka, U. The Pheromone-Based Harmony Search Algorithm for the Asymmetric Traveling Salesman Problem. Appl. Sci. 2020, 10, 6422. [CrossRef]

51. Al-harkan, I.M.; Qamhan, A.A.; Badwelan, A.; Alsamhan, A.; Hidri, L. Modified Harmony Search Algorithm for ResourceConstrained Parallel Machine Scheduling Problem with Release Dates and Sequence-Dependent Setup Times. Processes 2021, 9, 654. [CrossRef]

52. Çarbaş, S.; Saka, M.P. Optimum Topology Design of Various Geometrically Nonlinear Latticed Domes Using Improved Harmony Search Method. Struct. Multidisc. Optim. 2012, 45, 377-399. [CrossRef]

53. Wang, W.; Tian, J.; Lv, F.; Xin, G.; Ma, Y.; Wang, B. Mining Frequent Pyramid Patterns from Time Series Transaction Data with Custom Constraints. Comput. Secur. 2021, 100, 102088. [CrossRef]

54. Anwar, T.; Uma, V. CD-SPM: Cross-Domain Book Recommendation Using Sequential Pattern Mining and Rule Mining. J. King Saud Univ. Comput. Inf. Sci. in press. 2019. [CrossRef]

55. Hung, C.W. Using Cloud Services to Develop Marketing Information System Applications. J. Internet Technol. 2019, 20, 157-166. [CrossRef]

56. Tandon, N.; Varde, A.S.; de Melo, G. Commonsense Knowledge in Machine Intelligence. SIGMOD Rec. 2018, 46, 49-52. [CrossRef]

57. Pires, M.; Camanho, A.; Amorim, P. Solving the Grocery Backroom Sizing Problem. Int. J. Prod. Res. 2020, 58, 5707-5720. [CrossRef]

58. Rosales-Salas, J.; Maldonado, S.; Seret, A. Mining Sequences in Activities for Time Use Analysis. Intell. Data Anal. 2020, 24, 339-362. [CrossRef]

59. Epstein, L.D.; Flores, A.A.; Goodstein, R.C.; Milberg, S.J. A New Approach to Measuring Retail Promotion Effectiveness: A Case of Store Traffic. J. Bus. Res. 2016, 69, 4394-4402. [CrossRef]

60. Vu, H.Q.; Li, G.; Law, R.; Zhang, Y. Travel Diaries Analysis by Sequential Rule Mining. J. Travel Res. 2018, 57, 399-413. [CrossRef]

61. Lourenco, J.; Varde, A.S. Item-Based Collaborative Filtering and Association Rules for a Baseline Recommender in E-Commerce. In Proceedings of the 2020 IEEE International Conference on Big Data (Big Data), Atlanta, GA, USA, 10-13 December 2020; pp. $4636-4645$. 
62. Kim, H.-J.; Baek, J.-W.; Chung, K. Optimization of Associative Knowledge Graph Using TF-IDF Based Ranking Score. Appl. Sci. 2020, 10, 4590. [CrossRef]

63. Su, J.-H.; Liao, Y.-W.; Chen, L.-N. An Intelligent Course Decision Assistant by Mining and Filtering Learners' Personality Patterns. Appl. Sci. 2019, 9, 4665. [CrossRef]

64. Aloysius, G.; Binu, D. An Approach to Products Placement in Supermarkets Using PrefixSpan Algorithm. J. King Saud Univ. Comput. Inf. Sci. 2013, 25, 77-87. [CrossRef]

65. Degertekin, S.O.; Minooei, M.; Santoro, L.; Trentadue, B.; Lamberti, L. Large-Scale Truss-Sizing Optimization with Enhanced Hybrid HS Algorithm. Appl. Sci. 2021, 11, 3270. [CrossRef]

66. Kang, J.; Kwon, S.; Ryu, D.; Baik, J. HASPO: Harmony Search-Based Parameter Optimization for Just-in-Time Software Defect Prediction in Maritime Software. Appl. Sci. 2021, 11, 2002. [CrossRef]

67. Molina-Pérez, D.; Portilla-Flores, E.A.; Vega-Alvarado, E.; Calva-Yañez, M.B.; Sepúlveda-Cervantes, G. A Novel Multi-Objective Harmony Search Algorithm with Pitch Adjustment by Genotype. Appl. Sci. 2021, 11, 8931. [CrossRef]

68. Mahalingam, S.K.; Nagarajan, L.; Salunkhe, S.; Nasr, E.A.; Davim, J.P.; Hussein, H.M.A. Harmony Search Algorithm for Minimizing Assembly Variation in Non-Linear Assembly. Appl. Sci. 2021, 11, 9213. [CrossRef]

69. Pei, J.; Han, J.; Mortazavi-Asl, B.; Wang, J.; Pinto, H.; Chen, Q.; Dayal, U.; Hsu, M.-C. Mining Sequential Patterns by PatternGrowth: The PrefixSpan Approach. IEEE Trans. Knowl. Data Eng. 2004, 16, 1424-1440. [CrossRef]

70. Chaudhari, M.; Mehta, C. Extension of Prefix Span Approach with GRC Constraints for Sequential Pattern Mining. In Proceedings of the 2016 International Conference on Electrical, Electronics, and Optimization Techniques (ICEEOT), Chennai, India, 3-5 March 2016; pp. 2496-2498.

71. Varghese, C.; Pathak, D.; Varde, A.S. SeVa: A Food Donation App for Smart Living. In Proceedings of the 2021 IEEE 11th Annual Computing and Communication Workshop and Conference (CCWC), Virtual Conference, 27-30 January 2021; pp. 408-413.

72. Мa, X.; Ye, L. Career Goal-Based e-Learning Recommendation Using Enhanced Collaborative Filtering and Prefixspan. Int. J. Mob. Blended Learn. 2018, 10, 23-37. [CrossRef]

73. Kang, J.-S.; Baek, J.-W.; Chung, K. PrefixSpan Based Pattern Mining Using Time Sliding Weight From Streaming Data. IEEE Access 2020, 8, 124833-124844. [CrossRef]

74. Niyazmand, T.; Izadi, I. Pattern Mining in Alarm Flood Sequences Using a Modified PrefixSpan Algorithm. ISA Trans. 2019, 90, 287-293. [CrossRef] [PubMed]

75. Heragu, S. Facilities Design, 4th ed.; CRC Press: Boca Raton, FL, USA, 2016.

76. Tompkins, J.; White, J.; Bozer, Y.; Tanchoco, J. Facilities Planning, 4th ed.; Wiley: Hoboken, NJ, USA, 2010. 